
\title{
$\begin{array}{ll}\text { Research Square } & \begin{array}{l}\text { Preprints are preliminary reports that have not undergone peer review. } \\ \text { They should not be considered conclusive, used to inform clinical practice, } \\ \text { or referenced by the media as validated information. }\end{array}\end{array}$
}

\section{Neoadjuvant Pembrolizumab and Chemotherapy in Resectable Esophageal Cancer: An Open-Label, Multicenter, Single-Arm Study}

\section{Hongtao Duan}

Air Force Medical University 2nd Affiliated Hospital: Air Force Medical University Tangdu Hospital

Changjian Shao

Air Force Medical University 2nd Affiliated Hospital: Air Force Medical University Tangdu Hospital

Xiaobin Shang

Tianjin Medical College: Tianjin Medical University

Honggang Liu

Air Force Medical University 2nd Affiliated Hospital: Air Force Medical University Tangdu Hospital

Xiaoping Dong

Air Force Medical University 2nd Affiliated Hospital: Air Force Medical University Tangdu Hospital

Yong Zhang

Air Force Medical University 2nd Affiliated Hospital: Air Force Medical University Tangdu Hospital

Liping Tong

Air Force Medical University Tangdu Hospital

Yingtong Feng

Air Force Medical University 2nd Affiliated Hospital: Air Force Medical University Tangdu Hospital

\section{Yongan Zhou}

Air Force Medical University 2nd Affiliated Hospital: Air Force Medical University Tangdu Hospital

Yuanyuan Wang

Air Force Medical University 2nd Affiliated Hospital: Air Force Medical University Tangdu Hospital

Lu Wang

Air Force Medical University Xijing Hospital: Xijing Hospital

Minghong Pan

Air Force Medical University 2nd Affiliated Hospital: Air Force Medical University Tangdu Hospital

\section{Neil B. Newman}

Vanderbilt University Medical Center

Inderpal S. Sarkaria

University of Pittsburgh School of Medicine

John V Reynolds

St. James's Hospital

Francesco De Cobelli

IRCCS San Raffaele Scientific Institute

Hongjing Jiang

Tianjin Medical College: Tianjin Medical University

Tao Jiang

Air Force Medical University 2nd Affiliated Hospital: Air Force Medical University Tangdu Hospital

Xiaolong Yan ( $\nabla$ yanxiaolong@fmmu.edu.cn )

Tangdu Hospital Fourth Military Medical University: Air Force Medical University Tangdu Hospital https://orcid.org/0000-0003-2419-9707

\section{Research}

Keywords: pembrolizumab, chemotherapy, resectable esophageal cancer, efficacy, safety, pathological complete response (pCR), major pathological response (MPR).

Posted Date: August 3rd, 2021

DOI: https://doi.org/10.21203/rs.3.rs-749849/v1 
License: (c) (i) This work is licensed under a Creative Commons Attribution 4.0 International License. Read Full License 


\section{Abstract}

Background: Multimodal therapies, such as perioperative chemotherapy and neoadjuvant chemoradiotherapy together with surgical advances, have improved the outcomes of patients with resectableesophageal cancer (EC). However, the 5-year survival of these patients remains below $50 \%$. The advent of immunotherapy has resulted in novel approaches to advanced or metastatic disease, but the role of immunotherapy in the neoadjuvant settings has not yet to be established. In this single-arm study, the efficacy and safetyofneoadjuvant pembrolizumab plus chemotherapy were evaluatedin patients with resectableesophageal squamous cell carcinoma (ESCC).

Methods: This study was conducted at 2 hospitals(in Xi'an and Tianjin)and included patients with ESCC of clinical stage II-IVAwho underwent surgery within 4 to 6 weeks after completing treatment withpembrolizumab(200mg) combined with a conventional chemotherapy regimen (3 cycles). The efficacy and safety of this combination treatment were evaluated as primary endpointsof the study. This study was retrospectively registered (Registration number: ChiCTR2100048917).

Results:A total of 22 patients (including 18 men) were enrolled, of whom 17 patients progressed to surgery, 4 patients refused surgery due to tumor regression and symptomatic relief, and 1 patient had progressive disease. As determinedby the Response Evaluation Criteria in Solid Tumors(RECIST,version 1.1), 7 patients (31.8\%) had a partial response and 4 (18.2\%) patients hada complete response, which translated to an objective response rate of $50 \%$. The symptom remission rate was $90.9 \%$ according to the Stooler classification. Five patients (22.7\%) experienced serious treatment-related adverse events of grade 3-4 (including anorexia, vomiting, fatigue, alopecia and hypoadrenalism). Postoperative pathology revealed a major pathological response in 14 cases (82.3\%) and a complete pathological response in 8 cases (47.1\%). Programmed death-ligand 1expression in pretreatment specimens was not significantly associated with the percentage of residual viable tumor (RVT)( $r=-0.55$, $p=0.08)$. Changes in counts of CD68+ macrophage between pre- and post-treatment specimens wereweakly correlated with RVT( $\mathrm{r}=0.71 ; p=0.07)$, while a positive correlation was observed between postoperative Foxp3+T cells/CD4+Tcellsratios and RVT( $\mathrm{r}=0.84, p=0.03)$.

Conclusion: The combination of neoadjuvantimmunotherapy and chemotherapy for ESCC is associated with a high pathological response and immunologic effects in the tumor microenvironment. It has acceptable toxicity and great efficacy, suggesting a strong rationale for its further evaluation in randomized clinical trials.

Trial registration: ChiCTR, ChiCTR2100048917. Registered 19 July 2021 - Retrospectively registered, https://www.chictr.org.cn/edit.aspx? pid $=130073 \&$ htm $=4$

\section{Background}

Esophageal cancer (EC) is the 7th most common cancer-related death globally. In China, it is the $6_{\text {th }}$ most common malignancy, with esophageal squamous cell carcinoma (ESCC) being the dominant subtype ${ }^{1}$. The medianoverall survival (OS) of patients with advanced or metastatic esophageal cancer is extremely poor. For patients who have underwent surgeries alone, overall survival (OS) rates are improving; nonetheless, the five-year survival ratedoes not exceed $50 \%(49.1 \%)^{2}$.

According to the current National Comprehensive Cancer Network (NCCN) guidelines, multimodal therapy with neoadjuvant chemoradiotherapy is the recommended standard therapy for patients with T2-4aNxM0 resectable ESCC.The CROSS Study is the definitive modern randomized clinical trial (RCT),with an OS of 48.6 months versus 24.0 months in the multimodal and surgery-only cohorts, respectively ${ }^{3}$. However, a major limitationfor this treatment may be aheightened risk of major respiratory complications $₫$ including pneumonia, acute respiratory distress syndrom, respiratory failure and pulmonary embolism囚and mortality postoperatively ${ }^{4}$.Consequently,with the advent of a greater understanding of EC tumor biology and genomics, novel approaches whichcombine efficacy and safety are being explored.

In this regard, there is currently enormous interest in therapies that target the immune cells within the tumor microenvironment (TME). Programmed cell death protein-1 (PD-1) inhibitors have been evaluated in multiple clinical trials.In the KEYNOTE-181 study,pembrolizumab VS chemotherapy was evaluated as a second-line treatment foradvanced (unresectable or metastatic)EC. For patients with PD-L1 combined positive score (CPS) $\geq 10$, the 12 -month OS rate was $43 \%$ in the pembrolizumab group and $20 \%$ in the chemotherapy group ${ }^{5}$. And in the KEYNOTE-590 trail,combination of pembrolizumab and chemotherapy VS chemotherapy was evaluated as a first-line treatment for the unresectable or metastaticEC.The survival rate at 12 monthsof ESCC was higher with chemoimmunotherapy versus chemotherapy $\left(51 \%\right.$ VS38\% ${ }^{6}$. In the neoadjuvant treatment ofnon-small cell lung cancer (NSCLC), PD-1 inhibitors have produced excellent results.In the NCT02716038 study, NADIM study and our recent trial, neoadjuvant chemoimmunotherapy in resectableNSCLC reported encouragingdata of pathologicalresponse, with MPR $\left(57 \%, 83 \%, 50 \%\right.$ respectively)and pCR $(33 \%, 63 \%, 30 \% \text { respectively })^{7,8,9}$.

Given these encouraging trends for neoadjuvant regimens including anti-PD-1 therapy, the present study aimed to explore the safety and efficacy of anti-PD-1 therapy combined with chemotherapy for resectable ESCC in the neoadjuvant settings. We also preliminarily explore the correlations between pathological response and immunological parameters of the tumor microenvironment (TME). 


\section{Methods}

\subsection{Experimental design}

\subsubsection{Inclusion criteria}

In this single-arm study, 22patients were enrolled from2 hospitals in China (TangduHospital, Air Force Medical University and Cancer Institute and Hospital, Tianjin Medical University).Patients gave their informed consent to participate in the study, and the study was approved by the Ethics Committee of Tangdu Hospital of the Fourth Military Medical University (approval no.202005-12-KY-07-XW-01).Patients over the age of 18 years old withhistologically confirmed, treatment-naïveESCC of clinical stages II-IVA (according to the American Joint Committee on Cancer [AJCC 8th edition]) were eligible for inclusion. The key exclusion criteria were:patients withactive autoimmune disease; patients withactive concurrent malignancy; andpatients receiving ongoing systemic steroids(>10 mg daily prednisone equivalents) or other immunosuppressive therapy.

All of the includedpatients were scheduled to receivethe following drugs intravenously:pembrolizumab (200mg) combined with conventional chemotherapy for three 21-day cyclesprior to surgical resection(Table 1).Surgery was plannedwithin 4-6 weeks afterthe completion of the induction regimen. McKeown or IvorLewis esophagectomy, including two-field lymphadenectomy with totalmediastinal lymph node dissection was performed according to standard institutional procedures.

\subsection{Primary endpoints}

\subsubsection{Safety}

Adverse events (AEs) were assessed according to the Common Terminology Criteria for Adverse Events (CTCAE) V.4.0.

\subsubsection{Efficacy}

Efficacy was measured according to the following criteria: (1)Pathological complete response (pCR), defined as the complete absence of tumor cells, or major pathological response (MPR), defined as $<10 \%$ residual viable tumor (RVT), or incomplete pathological response, defined as $\geq 10 \%$ RVT (non-MPR/non-PCR) ${ }^{10}$;(2)Symptom remission, according to the Stooler classification ${ }^{11}$;(3)Treatment radiographic response,as determined using the Response Evaluation Criteria in Solid Tumors (RECISTversion1.1区.

\subsection{Evaluation of immunologic parameters}

Forkhead box P3-positive (Foxp3),CD4-positive and CD8-positive tumor-infiltrating lymphocytes were compared between pre-treatment biopsy specimens and surgical specimens using multiplex immunofluorescence (mIF) (Shanghai Baili Biotechnology Co. Ltd, Shanghai, China). CD68positive macrophagesand the expression of Programmed death-ligand 1 (PD-L1), tumor necrosis factor alpha (TNF)-a, and transforming growth factor beta 1 (TGF)- $\beta 1$ were also analyzedby immunohistochemistry (online supplementary methods). The Foxp3+T cells/(CD4+T cells) ratios and Foxp3+T cells/(CD8+T cells) ratios were calculated.

\subsection{Statistical analysis}

Demographic and safety data, aswell as clinical, pathologic, radiographic, and molecular response data, were recorded using descriptive statistics. The associations between RVT and pretreatment PD-L1 expression were analysed using Spearman's correlation analysis. Furthermore, the associations of RVT and other pretreatment and posttreatment immune parameters combined with their changes were analysed using Spearman's correlation analysis, including the expression of TNF- $a$, TGF- $\beta 1$ and the counts of Foxp3+ CD4+, CD8+ T cells and CD68+ macrophages. Similarly, the associations of RVT and pretreatment and posttreatment Foxp3+T cells/ (CD4+T cells) ratios and Foxp3+T cells/(CD8+T cells) ratios combined with their changes were analysed using Spearman's correlation analysis. Additionally, the differences in pathological complete response between patients whose PD-L1 combined positive score (CPS $\geq 10)$ and CPS $₫ 10$ were analysed with $\chi^{2}$ test.All $p$ values reported are 2-sided, with the significance level set at 0.05. Statistical analyses were performed using SPSS 19.0.

\section{Results \\ 2.1Efficacy}

Patients' characteristics and pathological response data are summarized in Table 1. This study enrolled 22 patients (18 men and 4 women), of whom 17 patients progressed to surgery, 4 patients refused surgery due to significant tumor regression and symptomatic relief, and 1 patient experienced disease progression (patient 22) and was given definitive chemoradiotherapy. According to RECIST 1.1, 7 patients (31.8\%) had a partial response (PR) and 4 patients (18.2\%) attained a complete response (CR), which translated to an objective response rate (ORR) of 50\% (Fig. 1). According to the Stooler classification, prior to neoadjuvant treatment, 5 patients had stenosis of grade 3 and 17 patients had stenosis of grade 2 . When after therapy, 18 patients had grade 0 symptoms, 2 patients had grade 1 symptoms, and 2 patients had grade 2 symptoms, with a 
symptom remission rate of $90.9 \%$ (Fig. 2). Postoperative pathological response revealed a pCR in 8 cases (47.1\%), and an MPR in 14 cases (82.3\%). Figure 1 shows representative imaging and pathology of a patient with pCR. The most recent follow-up took place on 15th December, 2020. One patient (patient 3) experienced recurrence and metastasis within 1 month postoperatively, and his immunotherapy was stopped. 


\begin{tabular}{|c|c|c|c|c|c|c|c|c|c|c|c|}
\hline $\begin{array}{l}\text { Patient } \\
\text { no. }\end{array}$ & Sex & $\begin{array}{l}\text { Age } \\
\text { (years) }\end{array}$ & $\begin{array}{l}\text { Location } \\
\text { of tumor }\end{array}$ & $\begin{array}{l}\text { Clinical } \\
\text { TNM } \\
\text { (cTNM) }\end{array}$ & Chemotherapy & Cycles & $\begin{array}{l}\text { RECIST } \\
1.1\end{array}$ & $\begin{array}{l}\text { Post- } \\
\text { neoadjuvant } \\
\text { therapyTNM } \\
\text { (ypTNM) }\end{array}$ & PCR/MPR & RVT\% & $\begin{array}{l}\text { PD-L1 } \\
\text { Combined } \\
\text { Positive } \\
\text { Score, } \\
\text { (CPS) }\end{array}$ \\
\hline P1 & $\mathrm{F}$ & 59 & Middle & cT3N1M0 & $\begin{array}{l}\text { Docetaxel } \\
\left(75 \mathrm{~m} / \mathrm{m}^{2}, \mathrm{D} 1\right) \\
\text { +Nedaplatin } \\
\left(80 \mathrm{~m} / \mathrm{m}^{2}, \mathrm{D} 1\right)\end{array}$ & 3 & $\begin{array}{l}\text { Non- } \\
\text { CR/Non- } \\
\text { PD }\end{array}$ & yрTONOMO & PCR & 0 & \\
\hline P2 & M & 66 & Middle & cT3N1M0 & $\begin{array}{l}\text { Nab-paclitaxel } \\
(260 \\
\text { mg/m²,D1) } \\
\text { +Nedaplatin } \\
\left(80 \mathrm{~m} / \mathrm{m}^{2}, \mathrm{D} 1\right)\end{array}$ & 3 & $\begin{array}{l}\text { Non- } \\
\text { CR/Non- } \\
\text { PD }\end{array}$ & ypT3N1M0 & MPR & $\leq 10$ & 30 \\
\hline P3 & M & 54 & Middle & cT4N1M0 & $\begin{array}{l}\text { Docetaxel } \\
\left(75 \mathrm{~m} / \mathrm{m}^{2}, \mathrm{D} 1\right) \\
\text { +Nedaplatin } \\
\left(80 \mathrm{~m} / \mathrm{m}^{2}, \mathrm{D} 1\right)\end{array}$ & 3 & SD & ypT4NOMO & & 70 & $<1$ \\
\hline P4 & M & 56 & Middle & cT3N2M0 & $\begin{array}{l}\text { Docetaxel } \\
\left(75 \mathrm{~m} / \mathrm{m}^{2}, \mathrm{D} 1\right) \\
\text { +Nedaplatin } \\
\left(80 \mathrm{~m} / \mathrm{m}^{2}, \mathrm{D} 1\right)\end{array}$ & 3 & PR & ypT3N2M0 & MPR & $\leq 10$ & 15 \\
\hline P5 & M & 35 & Distal & cT3N1M0 & $\begin{array}{l}\text { Nab-paclitaxel } \\
(260 \\
\left.\mathrm{mg} / \mathrm{m}^{2}, \mathrm{D} 1\right) \\
\text { +Nedaplatin } \\
\left(80 \mathrm{~m} / \mathrm{m}^{2}, \mathrm{D} 1\right)\end{array}$ & 3 & PR & ypTONOMO & PCR & 0 & 45 \\
\hline P6 & $\mathrm{F}$ & 51 & Middle & cT3N1M0 & $\begin{array}{l}\text { Docetaxel } \\
\left(75 \mathrm{~m} / \mathrm{m}^{2}, \mathrm{D} 1\right) \\
\text { +Nedaplatin } \\
\left(80 \mathrm{~m} / \mathrm{m}^{2}, \mathrm{D} 1\right)\end{array}$ & 3 & $\begin{array}{l}\text { Non- } \\
\text { CR/Non- } \\
\text { PD }\end{array}$ & урT4N0MO & & 65 & $<1$ \\
\hline P7 & M & 66 & Middle & cT3N2M0 & $\begin{array}{l}\text { Nab-paclitaxel } \\
(260 \\
\text { mg/m²,D1) } \\
\text { +Nedaplatin } \\
\left(80 \mathrm{~m} / \mathrm{m}^{2}, \mathrm{D} 1\right)\end{array}$ & 3 & PR & ypTONOMO & PCR & 0 & 10 \\
\hline P8 & M & 59 & Middle & cT3NOMO & $\begin{array}{l}\text { Nab-paclitaxel } \\
(260 \\
\left.\mathrm{mg} / \mathrm{m}^{2}, \mathrm{D} 1\right) \\
\text { +Nedaplatin } \\
\left(80 \mathrm{~m} / \mathrm{m}^{2}, \mathrm{D} 1\right)\end{array}$ & 3 & $\mathrm{CR}$ & урTONOMO & PCR & 0 & \\
\hline P9 & M & 59 & Middle & cT3NOMO & $\begin{array}{l}\text { Nab-paclitaxel } \\
(260 \\
\left.\mathrm{mg} / \mathrm{m}^{2}, \mathrm{D} 1\right) \\
\text { +Nedaplatin } \\
\left(80 \mathrm{~m} / \mathrm{m}^{2}, \mathrm{D} 1\right)\end{array}$ & 3 & $\begin{array}{l}\text { Non- } \\
\text { CR/Non- } \\
\text { PD }\end{array}$ & урT2NOMO & MPR & $\leq 10$ & \\
\hline P10 & M & 66 & Middle & cT3N1M0 & $\begin{array}{l}\text { Nab-paclitaxel } \\
(260 \\
\text { mg/m²,D1) } \\
\text { +Nedaplatin } \\
\left(80 \mathrm{~m} / \mathrm{m}^{2}, \mathrm{D} 1\right)\end{array}$ & 3 & PR & урTONOMO & PCR & 0 & 20 \\
\hline P11 & M & 64 & Middle & cT3N1M0 & $\begin{array}{l}\text { Nab-paclitaxel } \\
(130 \\
\text { mg/m²,D1,8) } \\
\text { +Nedaplatin } \\
\left(80 \mathrm{~m} / \mathrm{m}^{2}, \mathrm{D} 1\right)\end{array}$ & 3 & $\begin{array}{l}\text { Non- } \\
\text { CR/Non- } \\
\text { PD }\end{array}$ & ypTON1M0 & MPR & $\leq 10$ & \\
\hline P12 & $\mathrm{F}$ & 65 & Middle & cT3NOMO & $\begin{array}{l}\text { Nab-paclitaxel } \\
(130 \\
\left.\mathrm{mg} / \mathrm{m}^{2}, \mathrm{D} 1,8\right) \\
\text { +Nedaplatin } \\
\left(80 \mathrm{~m} / \mathrm{m}^{2} \llbracket \mathrm{D} 1\right)\end{array}$ & 3 & $\mathrm{CR}$ & урTONOMO & PCR & 0 & 16 \\
\hline
\end{tabular}




\begin{tabular}{|c|c|c|c|c|c|c|c|c|c|c|c|}
\hline P13 & $\mathrm{F}$ & 57 & Middle & cT3NOMO & $\begin{array}{l}\text { Nab-paclitaxel } \\
(130 \\
\text { mg/m²,D1,8) } \\
\text { +Nedaplatin } \\
\left(80 \mathrm{~m} / \mathrm{m}^{2}, \mathrm{D} 1\right)\end{array}$ & 3 & $\mathrm{CR}$ & урTONOMO & PCR & 0 & 6 \\
\hline P14 & $M$ & 74 & Middle & cT3N3M0 & $\begin{array}{l}\text { Paclitaxel } \\
\text { liposome for } \\
\text { injection }(180 \\
\text { mg/m²,D1) } \\
\text { +Cisplatin } \\
\left(40 \mathrm{mg}^{2} \mathrm{D} 1-3\right)\end{array}$ & 3 & PR & урT1N1M0 & MPR & $\leq 10$ & \\
\hline P15 & $M$ & 46 & Distal & cT3N3M0 & $\begin{array}{l}\text { Paclitaxel } \\
\text { liposome for } \\
\text { injection (180 } \\
\text { mg/m²,D1) + } \\
\text { Cisplatin } \\
\text { (40mg, D1-3) }\end{array}$ & 3 & SD & урT2N2M0 & & & 10 \\
\hline P16 & $M$ & 52 & Distal & cT3N3M0 & $\begin{array}{l}\text { Paclitaxel } \\
\text { liposome for } \\
\text { injection }(180 \\
\text { mg/m²,D1) + } \\
\text { Cisplatin } \\
\text { (40mg. D1-3) }\end{array}$ & 3 & $\begin{array}{l}\text { Non- } \\
\text { CR/Non- } \\
\text { PD }\end{array}$ & урT1N0M0 & MPR & $\leq 10$ & 10 \\
\hline P17 & $M$ & 61 & Middle & cT3N2M0 & $\begin{array}{l}\text { Paclitaxel } \\
\text { liposome for } \\
\text { injection (180 } \\
\text { mg/m²,D1) + } \\
\text { Cisplatin } \\
\text { (40mg, D1-3) }\end{array}$ & 3 & PR & уртONOMO & PCR & $\leq 10$ & \\
\hline P18 & $M$ & 78 & Middle & cT3N1M0 & $\begin{array}{l}\text { Nab-paclitaxel } \\
(130 \\
\text { mg/m²,D1,8) } \\
\text { +Nedaplatin } \\
\left(80 \mathrm{~m} / \mathrm{m}^{2}, \mathrm{D} 1\right)\end{array}$ & 6 & $\begin{array}{l}\text { Non- } \\
\text { CR/Non- } \\
\text { PD }\end{array}$ & & & & \\
\hline P19 & $M$ & 67 & Middle & cT3NOMO & $\begin{array}{l}\text { Docetaxel } \\
\left(75 \mathrm{~m} / \mathrm{m}^{2}, \mathrm{D} 1\right) \\
\text { +Nedaplatin } \\
\left(80 \mathrm{~m} / \mathrm{m}^{2}, \mathrm{D} 1\right)\end{array}$ & 5 & $\mathrm{CR}$ & & & & \\
\hline P20 & $M$ & 71 & Distal & cT3N1M0 & $\begin{array}{l}\text { Nab-paclitaxel } \\
(130 \\
\text { mg/m²,D1,8) } \\
\text { +Nedaplatin } \\
\left(80 \mathrm{~m} / \mathrm{m}^{2}, \mathrm{D} 1\right)\end{array}$ & 6 & PR & & & & $<1$ \\
\hline P21 & $M$ & 67 & Distal & cT3NOMO & $\begin{array}{l}\text { Nab-paclitaxel } \\
(130 \\
\text { mg/m²,D1,8) } \\
\text { +Nedaplatin } \\
\left(80 \mathrm{~m} / \mathrm{m}^{2}, \mathrm{D} 1\right)\end{array}$ & 5 & $\begin{array}{l}\text { Non- } \\
\text { CR/Non- } \\
\text { PD }\end{array}$ & & & & \\
\hline P22 & $M$ & 67 & Middle & cT3NOMO & $\begin{array}{l}\text { Nab-paclitaxel } \\
(260 \\
\left.\mathrm{mg} / \mathrm{m}^{2}, \mathrm{D} 1\right) \\
\text { +Nedaplatin } \\
\left(80 \mathrm{~m} / \mathrm{m}^{2}, \mathrm{D} 1\right)\end{array}$ & 3 & PD & & & & $<1$ \\
\hline
\end{tabular}

\subsection{Safety and surgical complications}

AEs are shown in Table 2. None of the patients in the study discontinued treatment due to an AE. The most common treatment-related AEs of grade 1 or 2 were leukopenia, neutropenia, anorexia, vomiting, fatigue, and alopecia. Five (22.7\%) of 22 patients suffered a treatment-related AE of grade 3 or 4 including anorexia, vomiting, fatigue, alopecia, and hypoadrenalism. Hypothyroidism and hypoadrenalism were attributed as possibly being related to the immunotherapy. 
Table 2

Adverse events of therapy

\begin{tabular}{|c|c|c|c|c|}
\hline & Any grade & Grade 1-2 & Grade 3 & Grade 4 \\
\hline Anemia & 2 & 2 & & \\
\hline Leukopenia & 7 & 7 & & \\
\hline Neutropenia & 7 & 7 & & \\
\hline Immunethrombocytopenic purpura & 1 & 1 & & \\
\hline Anorexia & 8 & 7 & 1 & \\
\hline Vomiting & 9 & 8 & 1 & \\
\hline Diarrhea & 2 & 2 & & \\
\hline Fatigue & 10 & 9 & 1 & \\
\hline Alopecia & 11 & 9 & 2 & \\
\hline Hypothyroidism & 1 & 1 & & \\
\hline Adrenocortical hypothyroidism & 1 & & 1 & \\
\hline
\end{tabular}

Seventeen patients received surgery. Postoperative complications included hoarseness ( 6 cases, $35.2 \%$, with 1 patient requiring a tracheostomy due to recurrent laryngeal nerve injury; this patient recovered with endotracheal intubation), pneumonia (4 cases, $23.5 \%)$, empyema (3 cases, $17.6 \%$ ), atelectasis ( 2 cases, $11.7 \%$ ), heart failure ( 2 cases, $11.7 \%$ ), respiratory failure (1 case, $5.8 \%$ ), and anastomotic leak ( 1 case, $5.8 \%$ ). Patient 11 developed pneumonia on postoperative day 1 , after treatment with antimicrobial drugs, and his conditions gradually worsened until his death on postoperative day 22.

\subsection{Pathologic assessment and genomic analyses}

The data suggested that RVT was not significantly associated with pre-treatment PD-L1 expression ( $r=-0.55 ; p=0.08)$ (Fig. 4). Additionally, no significant differences in pathological complete response were identified between patients whose PD-L1 combined positive score (CPS $\geq 10$ ) and CPS $₫ 10$.

Further analysis showed that the changes in counts of CD68 + macrophage were found to be positively correlated with RVT ( $r=0.71 ; p=0.07)$ (Fig. 5A, D). To explore the relationship between inflammatory cytokines and RVT, immunohistochemical methods were adopted to examine preand post-treatment expression of TNF- $\alpha$ and TGF- $\beta 1$ in the pathologic specimens (Fig. 5B, C). In this study, the post-treatment expression of TGF$\beta 1$ was increased compared to the preoperative expression, and the changes in TGF- $\beta 1$ expression was positively correlated with RVT ( $r=0.65, p=$ 0.11 ) and possibly indicated a poor prognosis (Fig. 5E). However, the available data showed no significant correlation between the changes in TNF-a expression and RVT (Fig. 5F). The correlations of RVT and the parameters of lymphocyte populations stated above were further explored (Fig. 6A, B), with a positive correlation observed between postoperative Foxp3 + T cells/ (CD4 + T cells) ratios and RVT ( $r=0.84, p=0.03)($ Fig. $6 \mathrm{C})$, positive correlation observed between changes in Foxp3 + T cells/ (CD4 + T cells) ratios and RVT $(r=0.61, p=0.15)($ Fig. 6D) and negative correlation observed between the counts of postoperative CD8 $+\mathrm{T}$ cells and RVT $(r=-0.61, p=0.14)$ (Fig. $6 \mathrm{E})$. However, no direct correlation was found between other types of immune cells and RVT.

\section{Discussion}

Different from PALACE-1, which combines immunotherapy and Chemoradiotherapy for resectable esophageal cancer in the neoadjuvant settings, our study is the first to report on pembrolizumab combined with chemotherapy alone in the neoadjuvant treatment of EC ${ }^{12}$. Our study were done at two centers involving 22 patients, small sample size though, important observations were made.

Firstly, the pCR of $47.1 \%$ was high, not dissimilar to the rates observed with chemoradiation in the CROSS trial (in ESCC, $49 \%$ ) and the NEOCRTEC 5010 RCT $(43.2 \%)^{3,13}$. This level of pathological response has not been observed in previous studies with chemotherapy alone in neoadjuvant settings, of which the pCR were typically less than $20 \%(12.8 \%)^{14}$. Moreover, pCR and MPR are verified to confer a survival advantage and to prolong median disease-free survival in EC and in many other cancers ${ }^{10}$. To validate the DFS and OS benefits of neoadjuvant chemoimmunotherapy for ESCC, further exploration of this regimen could be done in this patient population.

We also evaluated the safety of the regimen. In our study, only 5 of 22 patients (22.7\%) experienced treatment-related AEs of grade 3 or 4 . The incidence of serious AEs appears to be acceptable, compared to the PALACE-1 study (65\%) and NADIM study (30\%) $)^{8,12}$. Furthermore, treatment with neoadjuvant pembrolizumab did not delay planned surgery. Immune-related AEs, both hypothyroidism and hypoadrenalism, were identified and relieved with supplementary treatment, with no delay to surgery. The single postoperative death $(1 / 17 ; 5.8 \%)$ which occurred in our study was 
also unrelated to the regimen, having been caused by microbiologically proven bacterial pneumonia and sepsis. This complication is distinct from reported immunotherapy-related pneumonitis, which can be ameliorated by steroids, but which had no impact on this patient ${ }^{15}$.

The associations between residual viable tumor (RVT) and the immunologic parameters are intriguing. In the TME, tumor cells, blood vessels, immune cells, lymphocytes, cancer stem cells, and cancer-associated fibroblasts mix, and there is considerable immune cell activity that may be stage- and context-dependent ${ }^{16}$. Macrophages are a key component of the TME. As the principal cells of antigen recognition and presentation, they secrete TNF-a, interleukin-1 $\beta$, and other cytokines, and impact the magnitude and type of T-cell response. Studies report that a high macrophage count was associated with poor $\mathrm{OS}^{17}$, and this conclusion may also account for the positive correlation between RVT and changed CD68 expression in the post-treatment pathologic tissues compared with the pre-treatment samples. Accordingly, CD68 expression may be predictive of a poor response to immunotherapy, and this requires further study. Immunosuppressive cells (i.e., regulatory $T$ cells [Tregs, Foxp3 + T]) are a part of infiltrating CD4 + T-cell in the TME, which significantly inhibit the T-cell-mediated anti-tumor effect and may be associated with Tcell dysfunction ${ }^{18,19}$. In other translational studies, Foxp3 $+\mathrm{T}$ cells in the TME of non-small cell lung cancer were associated with poor $0 S^{20}$, and in our study, a positive correlation between post-treatment Foxp3 + T cells/ (CD4 + T cells) ratios and RVT was confirmed in the context of ESCC, suggesting a prognostic role of post-treatment Foxp3 + T cells/ (CD4 + T cells) ratios. No direct correlation was found between the counts of other T cells and RVT. These results may be attributable to the time and space heterogeneity of immunotherapy, although the specific mechanism requires further study. TGF- $\beta 1$, TNF- $a$ and other cytokines in the TME also play key roles in regulating the response to immunotherapy ${ }^{21}$. Among these cytokines, immunoregulatory TGF- $\beta 1$ suppresses the proliferation of B-cell, cytotoxic T-cell, and natural killer cell and antagonizes the biological effects of TNF- $\mathrm{a}^{22}$. In other studies, it was reported that TGF- $\beta$ signalling may counteract anti-tumour immunity by restricting the movement of T-cells in the TME ${ }^{23}$. We hypothesized that the increases in TGF- $\beta$ may predict poor pathological response. This hypothesis was supported by our findings that changes in TGF- $\beta 1$ expression was positively correlated with RVT. It may be difficult that the small sample size in this study precluded a full analysis of the relationship between TNF- $\alpha$, TGF- $\beta 1$, and RVT, and further study is clearly required.

There are some limitations to this study that should be noted. Firstly, other markers of relevance including the genomic profile, tumor mutational burden, and the inflammatory factor interferon-gamma were not evaluated. A further limitation is the study's small sample size; however, since it is the first clinical trial of its kind, it still has important clinical observational significance to serve as the backbone for larger analyses. Another important aspect is that the OS of patients was not extensively explored, as the main endpoint of the study was safety. However, previous studies have shown that high pCR are closely related to patient OS, which will be the focus of our next study.

\section{Conclusions}

In conclusion, neoadjuvant chemoimmunotherapy is safe and feasible for patients with ESCC, with an extremely high pathological complete response and major pathological response and a clear impact on the TME. With adjuvant studies (such as Checkmate 577 trial) of anti-PD-1 therapy in EC having reported promising results, further RCTs and translational studies should be performed with this treatment paradigm, which appears to hold considerable potential. ${ }^{24}$

\section{Abbreviations}

AE:Adverse event;AJCC:American Joint Committee on Cancer;CT:computed tomography;CTCAE:Common Terminology Criteria for Adverse Events;CPS:combined positive score;CR:complete response;EC:esophageal cancer;ESCC:esophageal squamous cell carcinoma;IHC:Immunohistochemistry;mIF:multiplex immunofluorescence;MPR:major pathological response;NCCN:National Comprehensive Cancer Network;NSCLC:non-small cell lung cancer;ORR:objective response rate;OS:overall survival;PFS:progression-free survival;PR:partialresponse;pCR:pathological complete response;PD-1:Programmed cell death protein-1;PD-L1:Programmed death-ligand 1;RECIST:Response Evaluation Criteria in Solid Tumors;RVT:residual viable tumor;TME:tumor microenvironment;TNF-a:tumor necrosis factor alpha;TGF- $\beta 1$ :transforming growth factor beta 1 .

\section{Declarations}

\section{Ethics approval and consent to participate}

Patients provided informed consent to participate in the study. This study was approved by the Ethics Committee of Tangdu Hospital of the Fourth Military Medical University (approval No. 202005-12-KY-07-XW-01).

\section{Consent for publication}

Not applicable

\section{Availability of data and material}

All data generated or analysed during this study are included in this published article. 


\section{Competing interests}

The authors declare that they have no competing interests.

\section{Funding}

The present study was supported by grants from the National Natural Science Foundation of China (No. 81871866).

\section{Authors' contributions}

XLY, HJJ, and TJ contributed to the conception of the study; HTD, CJS, and XBS contributed significantly to writing the trial protocols; HGL, XPD, YZ, LPT, YTF, YYW, LW, and MHPhelped to perform the analysis with constructive discussions; LPT, YYW, LW, NBN, ISS, JVR, and FDCperformed the data analysis and wrote the manuscript. Manuscript writing: All authors. Final approval of manuscript: All authors.

\section{Acknowledgments}

The authors appreciate the academic support from AME Esophageal Cancer Collaborative Group.

\section{References}

1. Mao YS, Gao SG, Wang Q, Shi XT, Li Y, Gao WJ, et al. Analysis of a registry database for esophageal cancer from high-volume centers in China. Diseases of the esophagus : official journal of the International Society for Diseases of the Esophagus. 2020;33(8).

2. Yang H, Liu H, Chen Y, Zhu C, Fang W, Yu Z, et al. Long-term Efficacy of Neoadjuvant Chemoradiotherapy Plus Surgery for the Treatment of Locally Advanced Esophageal Squamous Cell Carcinoma: The NEOCRTEC5010 Randomized Clinical Trial. JAMA Surg. 2021.

3. Shapiro J, van Lanschot JJB, Hulshof MCCM, van Hagen P, van Berge Henegouwen MI, Wijnhoven BPL, et al. Neoadjuvant chemoradiotherapy plus surgery versus surgery alone for oesophageal or junctional cancer (CROSS): long-term results of a randomised controlled trial. Lancet Oncol. 2015;16(9):1090-8.

4. Kumagai K, Rouvelas I, Tsai JA, Mariosa D, Klevebro F, Lindblad M, et al. Meta-analysis of postoperative morbidity and perioperative mortality in patients receiving neoadjuvant chemotherapy or chemoradiotherapy for resectable oesophageal and gastro-oesophageal junctional cancers. The British journal of surgery. 2014;101(4):321-38.

5. Kojima T, Shah MA, Muro K, Francois E, Adenis A, Hsu CH, et al. Randomized Phase III KEYNOTE-181 Study of Pembrolizumab Versus Chemotherapy in Advanced Esophageal Cancer. Journal of clinical oncology : official journal of the American Society of Clinical Oncology. 2020;38(35):4138-48

6. Kato K, Shah MA, Enzinger P, Bennouna J, Shen L, Adenis A, et al. KEYNOTE-590: Phase III study of first-line chemotherapy with or without pembrolizumab for advanced esophageal cancer. Future Oncol. 2019;15(10):1057-66.

7. Shu CA, Gainor JF, Awad MM, Chiuzan C, Grigg CM, Pabani A, et al. Neoadjuvant atezolizumab and chemotherapy in patients with resectable non-small-cell lung cancer: an open-label, multicentre, single-arm, phase 2 trial. Lancet Oncol. 2020;21(6):786-95.

8. Provencio M, Nadal E, Insa A, García-Campelo MR, Casal-Rubio J, Dómine M, et al. Neoadjuvant chemotherapy and nivolumab in resectable non-small-cell lung cancer (NADIM): an open-label, multicentre, single-arm, phase 2 trial. Lancet Oncol. 2020;21(11):1413-22.

9. Duan H, Wang T, Luo Z, Tong L, Dong X, Zhang Y, et al. Neoadjuvant programmed cell death protein 1 inhibitors combined with chemotherapy in resectable non-small cell lung cancer: an open-label, multicenter, single-arm study. Translational lung cancer research. 2021;10(2):1020-8.

10. Topalian SL, Taube JM, Pardoll DM. Neoadjuvant checkpoint blockade for cancer immunotherapy. Science (New York, NY). 2020;367(6477)

11. Hong-Ke LI, Chen GF, Jian-Jie LI, Han YD, Yong-Juan SUJCR, Practice. Clinical effect of removable esophageal stent implantation and endoscopic probe dilatation in the treatment of refractory esophageal stricture. 2019.

12. Li C, Zhao S, Zheng Y, Han Y, Chen X, Cheng Z, et al. Preoperative pembrolizumab combined with chemoradiotherapy for oesophageal squamous cell carcinoma (PALACE-1). European journal of cancer (Oxford, England : 1990). 2021;144:232-41.

13. Yang H, Liu H, Chen Y, Zhu C, Fang W, Yu Z, et al. Neoadjuvant Chemoradiotherapy Followed by Surgery Versus Surgery Alone for Locally Advanced Squamous Cell Carcinoma of the Esophagus (NEOCRTEC5010): A Phase III Multicenter, Randomized, Open-Label Clinical Trial. Journal of clinical oncology : official journal of the American Society of Clinical Oncology. 2018;36(27):2796-803.

14. Ancona E, Ruol A, Santi S, Merigliano S, Sileni VC, Koussis H, et al. Only pathologic complete response to neoadjuvant chemotherapy improves significantly the long term survival of patients with resectable esophageal squamous cell carcinoma: final report of a randomized, controlled trial of preoperative chemotherapy versus surgery alone. Cancer. 2001;91(11):2165-74.

15. Naidoo J, Wang X, Woo KM, lyriboz T, Halpenny D, Cunningham J, et al. Pneumonitis in Patients Treated With Anti-Programmed Death1/Programmed Death Ligand 1 Therapy. Journal of clinical oncology : official journal of the American Society of Clinical Oncology. 2017;35(7):709-17. 
16. Fridman WH, Pagès F, Sautès-Fridman C, Galon J. The immune contexture in human tumours: impact on clinical outcome. Nature reviews Cancer. 2012;12(4):298-306.

17. Galluzzi L, Buqué A, Kepp O, Zitvogel L, Kroemer G. Immunological Effects of Conventional Chemotherapy and Targeted Anticancer Agents. Cancer cell. 2015;28(6):690-714.

18. Huang AC, Postow MA, Orlowski RJ, Mick R, Bengsch B, Manne S, et al. T-cell invigoration to tumour burden ratio associated with anti-PD-1 response. Nature. 2017;545(7652):60-5.

19. Galon J, Costes A, Sanchez-Cabo F, Kirilovsky A, Mlecnik B, Lagorce-Pagès C, et al. Type, density, and location of immune cells within human colorectal tumors predict clinical outcome. Science (New York, NY). 2006;313(5795):1960-4.

20. Liu J, O'Donnell JS, Yan J, Madore J, Allen S, Smyth MJ, et al. Timing of neoadjuvant immunotherapy in relation to surgery is crucial for outcome. Oncoimmunology. 2019;8(5):e1581530.

21. Pardoll DM. The blockade of immune checkpoints in cancer immunotherapy. Nature reviews Cancer. 2012;12(4):252-64.

22. Mariathasan S, Turley SJ, Nickles D, Castiglioni A, Yuen K, Wang Y, et al. TGF $\beta$ attenuates tumour response to PD-L1 blockade by contributing to exclusion of T cells. Nature. 2018;554(7693):544-8.

23. Batlle E, Massagué J. Transforming Growth Factor- $\beta$ Signaling in Immunity and Cancer. Immunity. 2019;50(4):924-40.

24. Kelly R. J. AJA, Kuzdzal J. et al. LBA9_PR Adjuvant nivolumab in resected esophageal or gastroesophageal junction cancer (EC/GEJC) following neoadjuvant chemoradiation therapy (CRT): First results of the CheckMate 577 study. Ann Oncol31(Supplement 4):S1193-4 (2020).

\section{Figures}

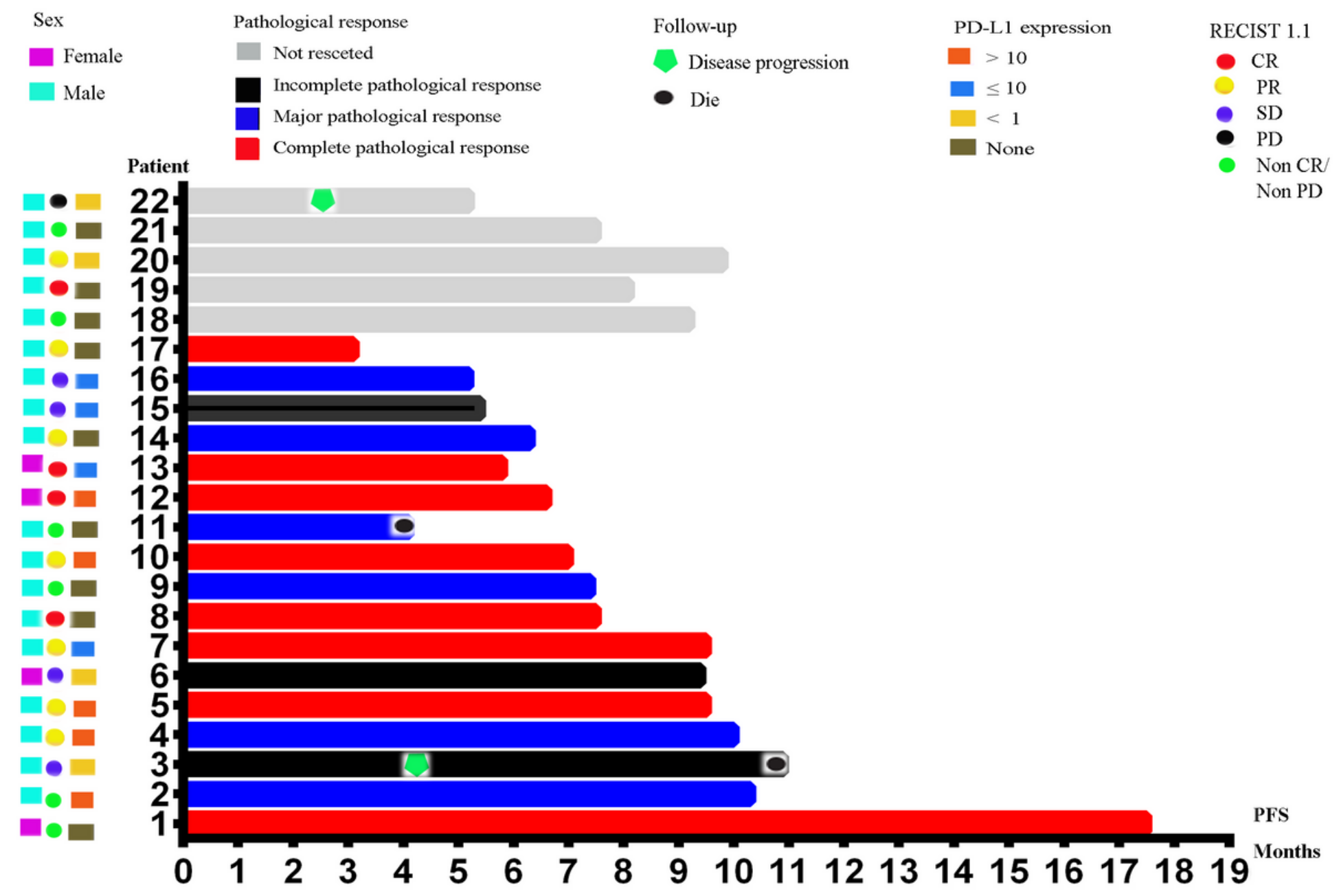

Figure 1

Swimmer plot of progression-free survival (PFS) in the modified intention-to-treat population ( $\mathrm{n}=22$ ). Each bar represents 1 patient. The left column shows clinical characteristics. 


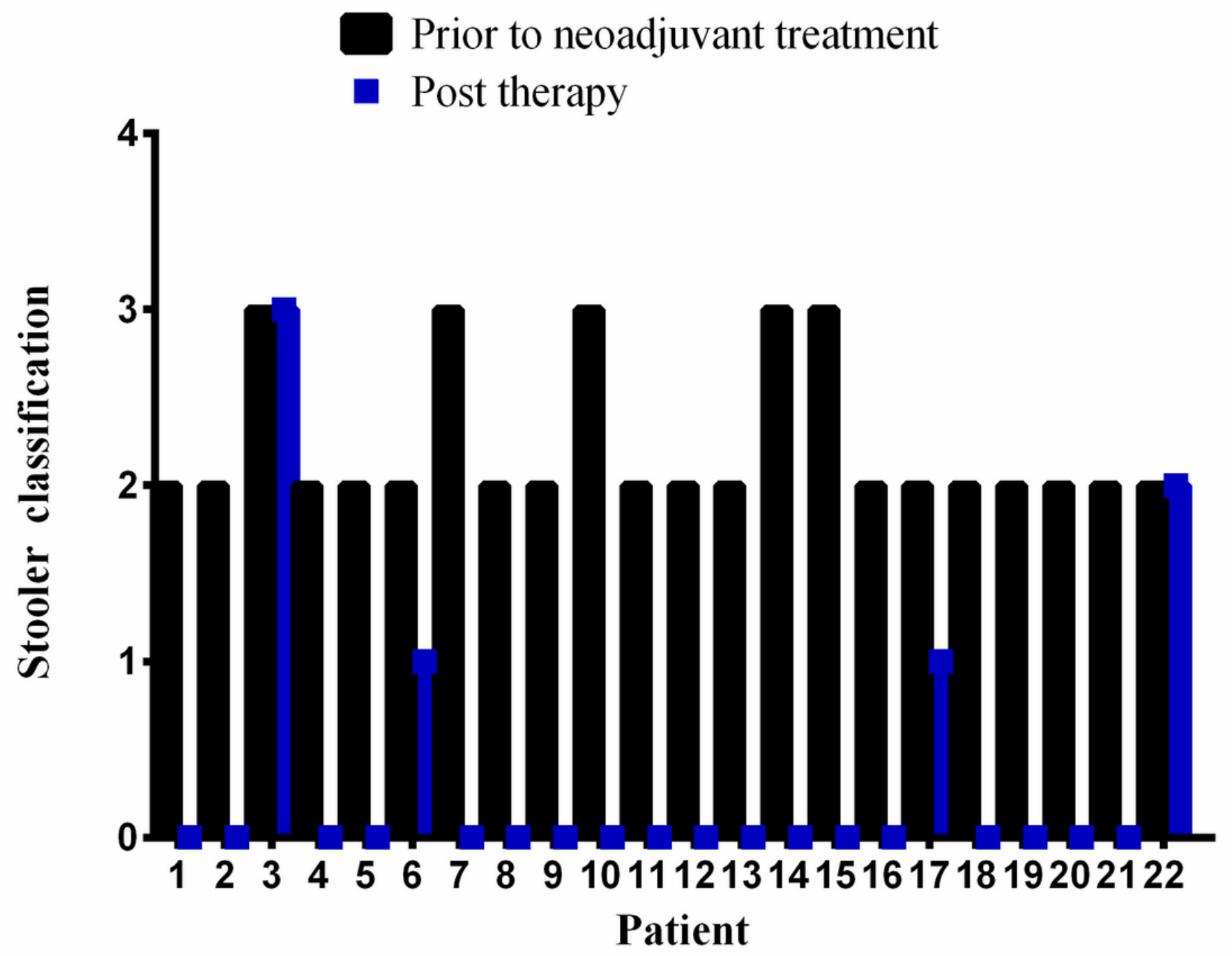

Figure 2

Symptom remission according to the Stooler classification. Black bar: prior to neoadjuvant treatment; blue bar: post therapy 


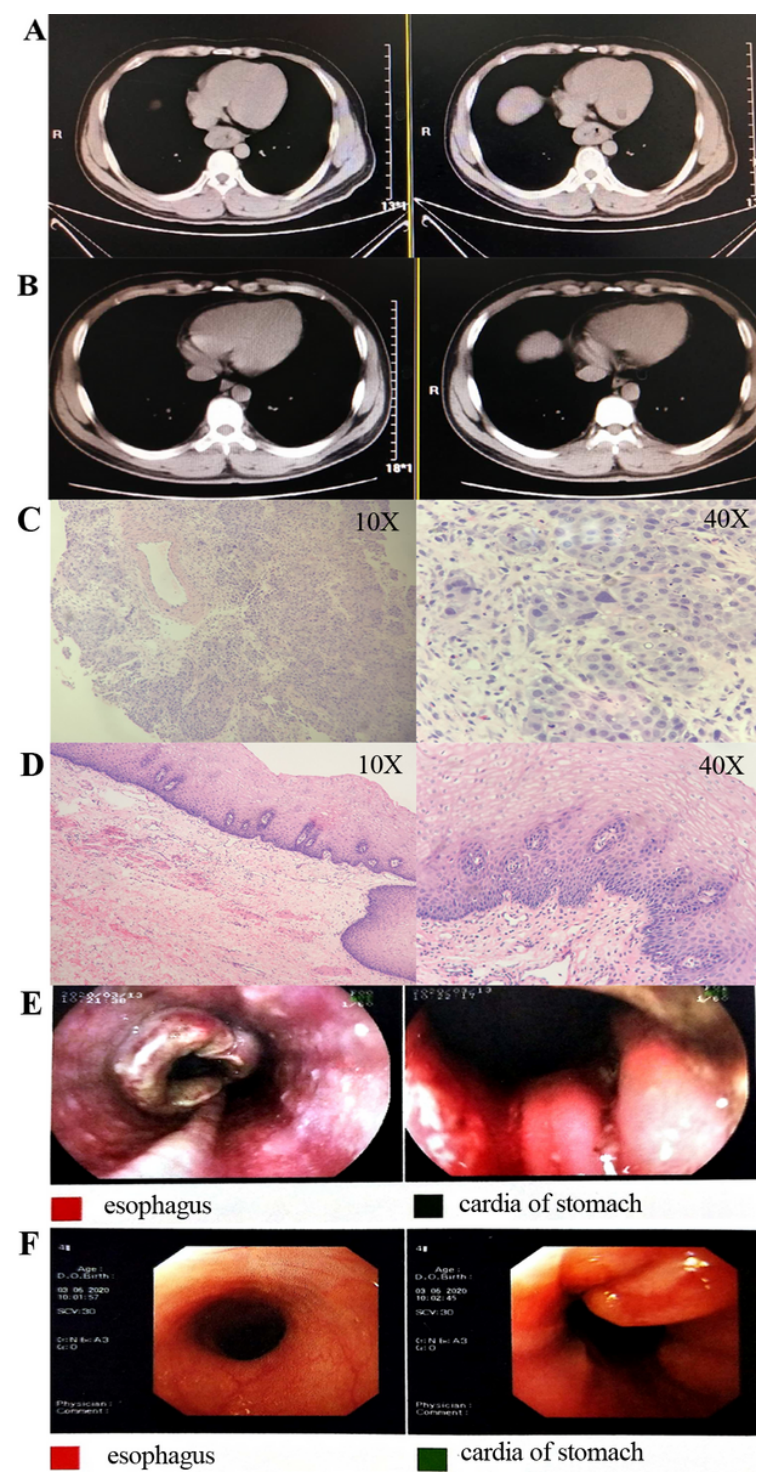

Figure 3

Representative images and pathology for a patient A: Pre-treatment computed tomography (CT) images; B: post-treatment CT images; C: pretreatment HE staining images; D: postoperativeHE staining images; E: pre-treatment gastroscopy images; F: post-treatmentgastroscopy images 


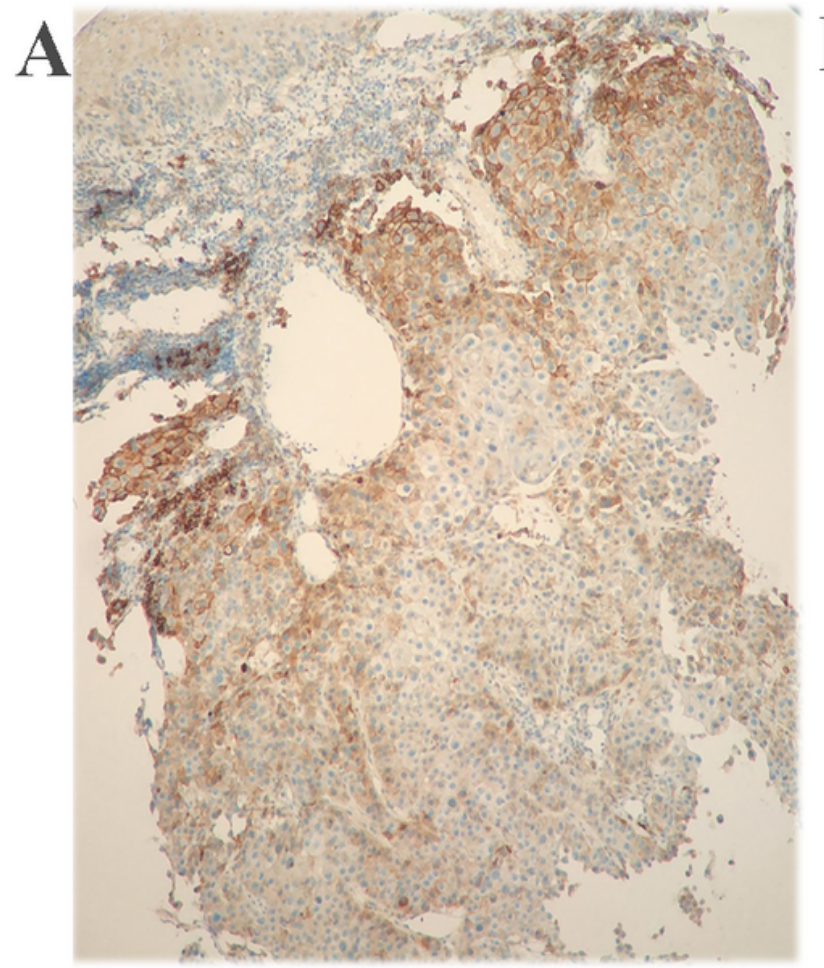

\section{B}

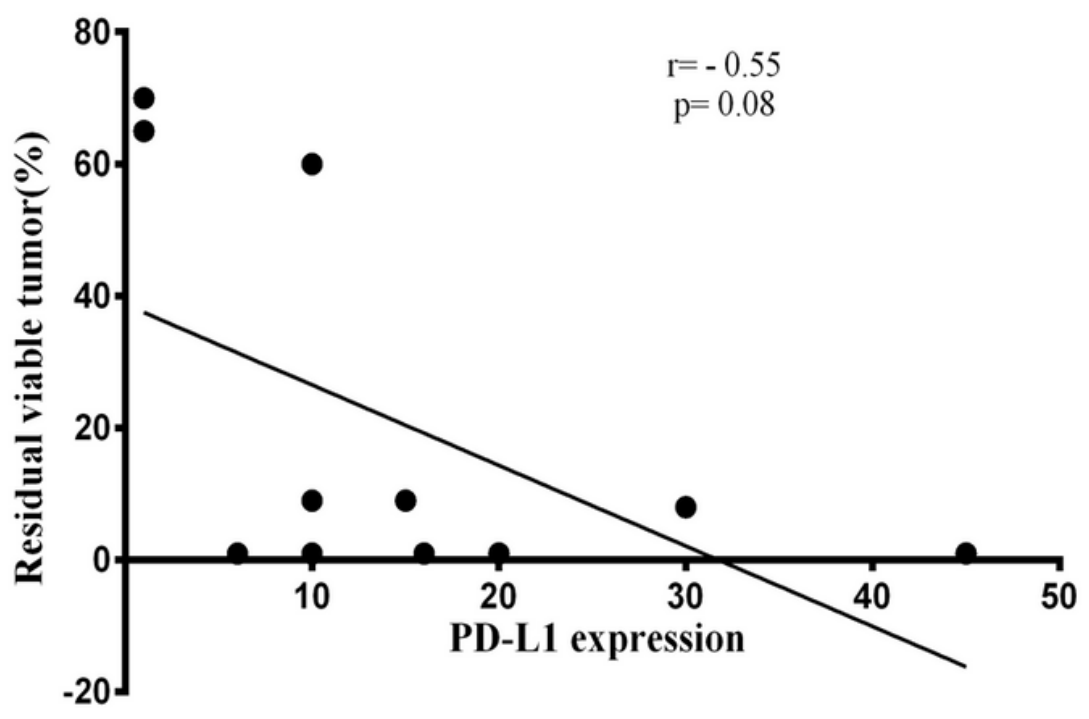

Figure 4

Correlation between PD-L1 expression and RVT A:Representative PD-L1 IHC image ofpre-treatmentspecimens B:Correlation analysis of PD-L1 expression and RVT
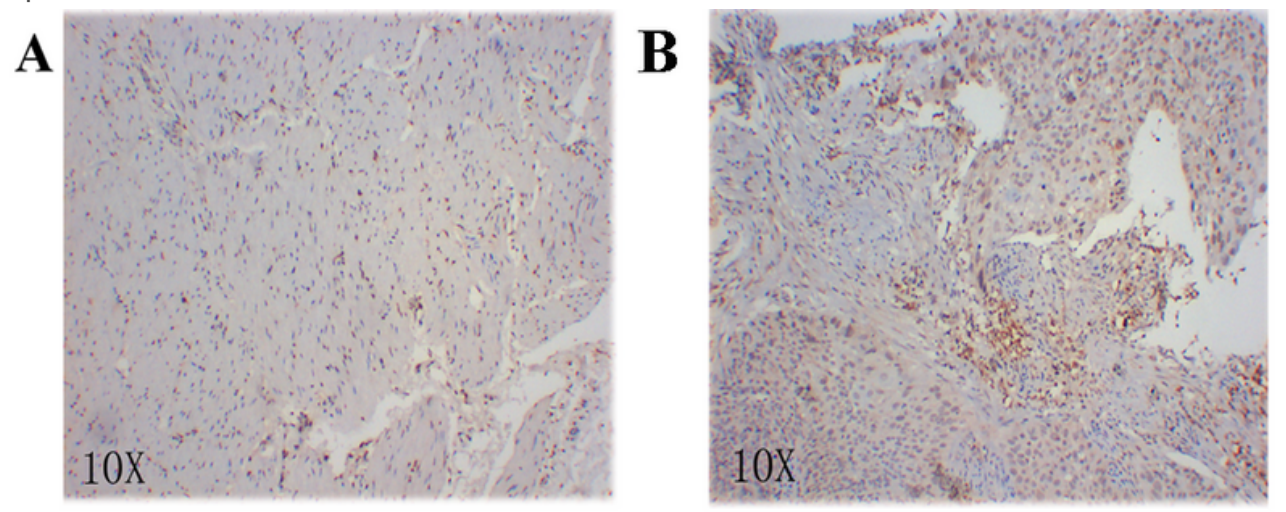

C
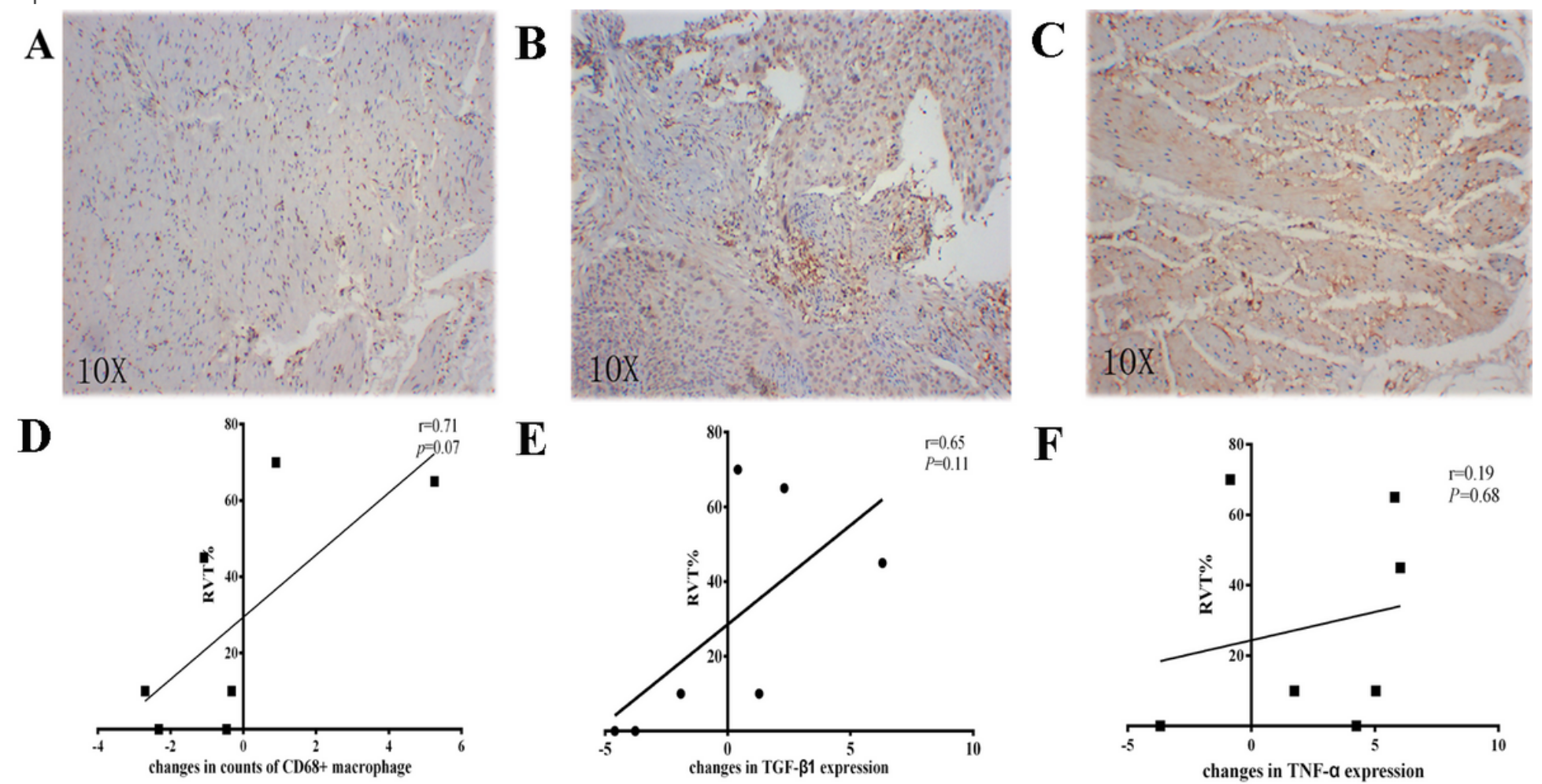

$\mathbf{E}$
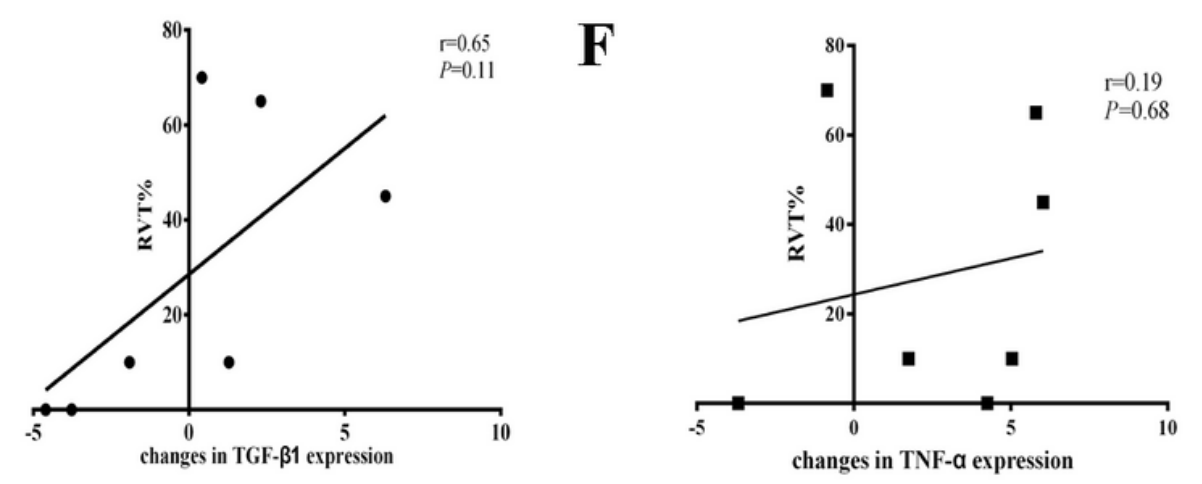

Figure 5

Correlation between inflammatory parameters and RVT A,B,C:Representative IHC image ofCD68, TGF- $\beta 1$ and TNF-a D: correlation analysis between changes in counts of CD68+ macrophage and RVT E: correlation analysis betweenchanges in TGF- $\beta 1$ expression and RVT F: correlation analysis betweenchanges in TNF-a expression and RVT 

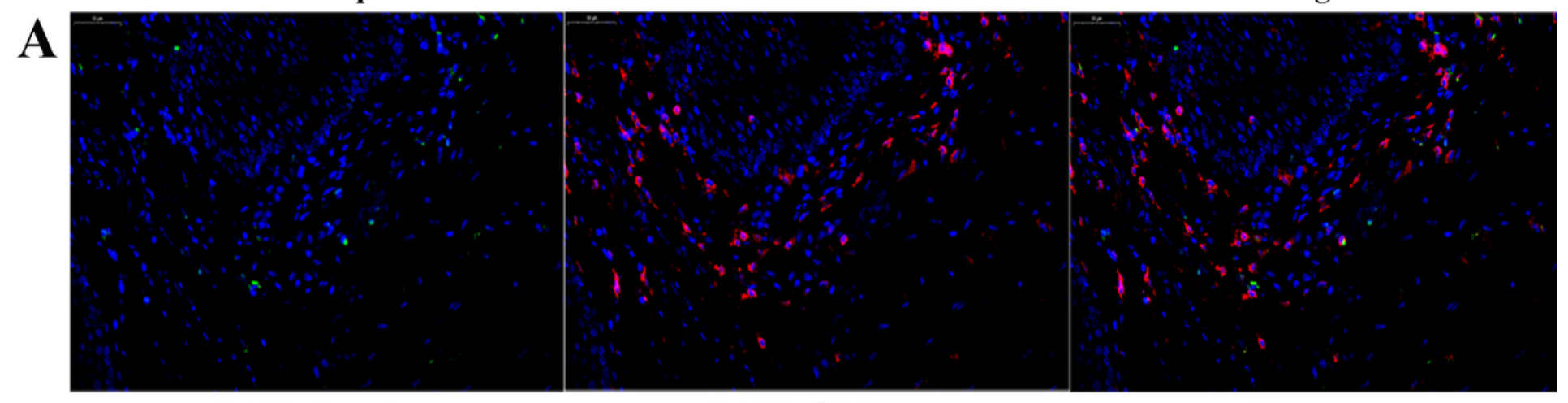

DAPI+Foxp3

DAPI+CD8

Merge
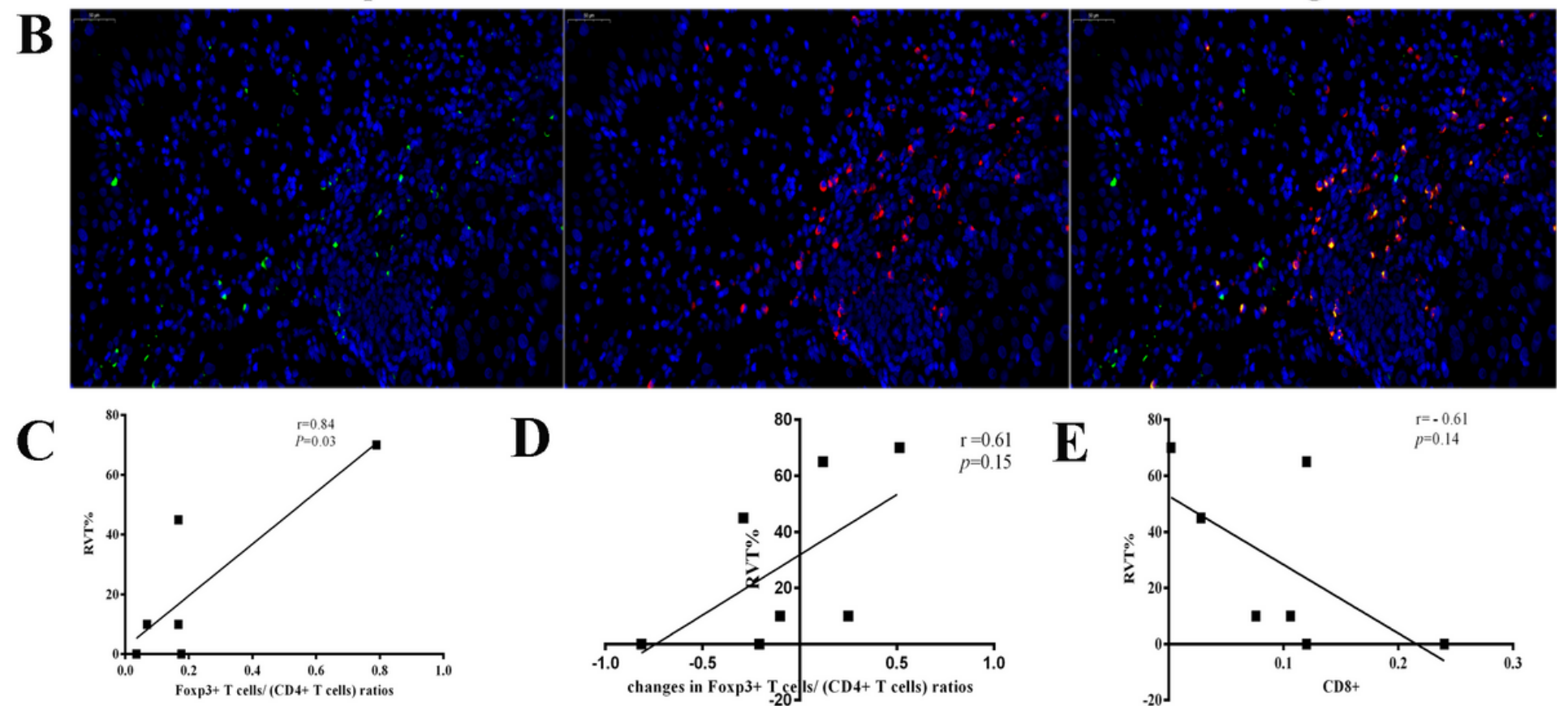

D
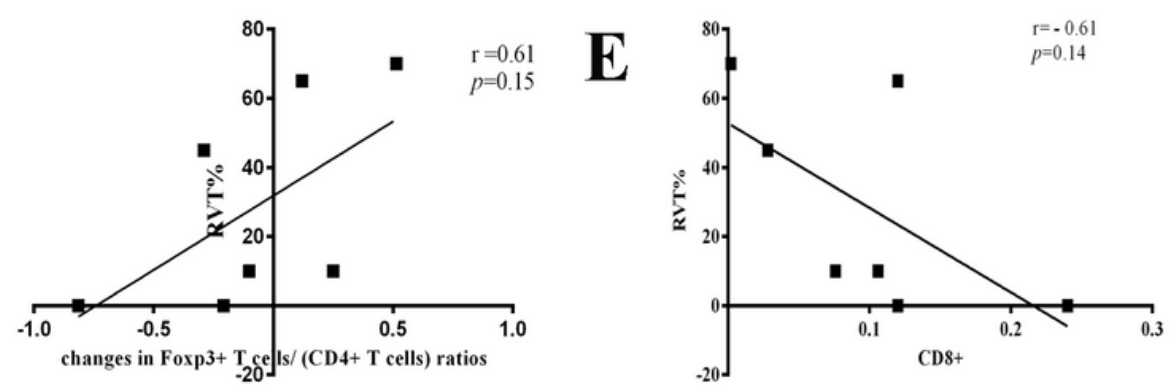

Figure 6

Correlation between immune cells and RVT A: Two-color Immunofluorescence analysis showing the expression of CD4, Foxp3. DAPI (blue), CD4 (red)and Foxp3(green). B:Two-color Immunofluorescence analysis showing the expression of CD8, Foxp3. DAPI (blue), CD8(red)and Foxp3(green). C: correlation analysis between postoperative Foxp3+ T cells/ (CD4+ T cells) ratios and RVT D: correlation analysis between changes in Foxp3+ T cells/ (CD4+ T cells) ratios and RVT E: correlation analysis between the counts of postoperative CD8+ T cells and RVT DAPI, DAPI fluorescence marking the cell nucleus. 